124 Literatura e Sociedade

\title{
"O NATAL DO VIÚvO" - OU O CORPO PARALISADO*
}

\section{Cristiane de Oliveira Fernandes Garcia}

Universidade de São Paulo

Resumo

Dentro dos dilemas vividos pela literatura contemporânea brasileira, principalmente nas duas últimas décadas do século $\mathrm{XX}$, interessa-nos, neste ensaio, o estudo da narrativa breve de Modesto Carone "O natal do viúvo", principalmente porque esse conto faz referência às questões da identidade e da subjetividade, como essas se apresentam em nossos dias, e trabalham a literatura como elemento crítico da sociedade. Este estudo tem como objetivo iniciar um diálogo a respeito da formalização estética de questões sociais presentes na narrativa do autor e espera poder contribuir para novas possibilidades de interpretação de sua obra dentro do painel da literatura contemporânea.

\section{Abstract}

Among the dilemmas experienced by contemporary Brazilian literature, especially over the last two decades of the twentieth century, I have chosen to discuss issues of identity and subjectivity, as they present themselves in the short story by Modesto Carone "O natal do viuvo". This study aims to investigate the aesthetic formalization of social issues present in Modesto Carone's and hopes to contribute to new possibilities of interpretating the Brazilian author's work within the reality of contemporary literature, understood as a critical element of society.

\author{
Palavras-chave \\ Modesto \\ Carone; \\ literatura \\ brasileira; conto \\ contemporâneo.
}

* Este artigo integra a dissertação de mestrado Ao redor do castelo: uma leitura das narrativas de Modesto Carone, defendida em março de 2010 na FFLCH-USP. 


\author{
Memória \\ Amar o perdido \\ deixa confundido \\ este coração. \\ Nada pode o olvido \\ contra o sem sentido \\ apelo do Não. \\ As coisas tangíveis \\ tornam-se insensíveis \\ à palma da mão \\ Mas as coisas findas \\ muito mais que lindas, \\ essas ficarão. \\ (Carlos Drummond de Andrade)
}

nédita em livro até 2007, quando integrou o volume Por trás dos vidros, a pequena narrativa "O natal do viúvo" já havia sido publicada na Folha de S.Paulo, Caderno Ilustrada, em 29 de agosto de 2000, e na revista Novos Estudos Cebrap, n.32, de março de 1992. Formada por apenas um parágrafo que ocupa pouco mais de duas páginas, a narrativa pode ser lida rapidamente, mas não sem certa dificuldade de apreensão do sentido, pois logo nas primeiras linhas torna-se evidente a dificuldade do narrador em expor a história.

De forma muito panorâmica, o conto nos apresenta, logo em seu início, a cena de um viúvo inominado que permanece sentado em um canto da sala escura de um sobrado também tomado pela penumbra em uma noite de Natal. No decorrer da exposição, há descrições da sala, do quintal, da rua. Em determinado ponto da narrativa, o real parece ficar tomado pelo que parece ser outro tempo, uma diversa realidade já não existente, mas que permanece somente para esse viúvo e inclui a presença da mulher, dos filhos e de detalhes de uma noite de Natal passada. Essa cena que emerge na narrativa dura pouco, a consciência da realidade retorna e tudo parece, novamente, escuro e sem movimento.

Embora a personagem principal da narrativa seja o viúvo e o enredo baseie-se nas circunstâncias que o envolvem - enredo esse que pode ser resumido em poucas palavras como fizemos -, não há como negar que existe um elemento mais instigante que sobressai durante a leitura. Esse elemento diz respeito ao narrador que organiza e nos apresenta as cenas. O conto é narrado em terceira pessoa, por uma voz que nos é desconhecida, uma entidade que observa ambiente e personagem sem conseguir configurar a ambos de forma objetiva. Esse fato já nos chama a atenção por diferir daquele que parece ser o típico narrador caroniano: o narrador em primeira pessoa. 
As poucas narrativas em terceira pessoa presentes em seus quatro livros ${ }^{1}$ trazem características muito peculiares, pois, dos seus 59 contos, apenas dez são escritos com esse foco narrativo. Desses dez, "Escombros", do livro Dias melhores, é o que apresenta o narrador em terceira pessoa da forma mais tradicional: uma voz que apenas conta o percurso de uma personagem ao perseguir uma mulher nas ruínas de uma cidade, descrevendo os percalços e dificuldades para poder se aproximar dela. Ao final da narrativa, constituída de quatro pequenos parágrafos, a personagem consegue apenas visualizá-la à luz de uma claraboia, embora não a consiga alcançar como pretendia.

O conto "Noites de circo", presente no livro As marcas do real, não chega a ser contabilizado no levantamento do foco narrativo de Modesto Carone feito por Cássio Tavares, ${ }^{2}$ pois esse acredita que não há como identificar o lugar de onde parte a voz narrativa, além de não haver a configuração de um protagonista. De modo geral, essa narrativa apresenta uma voz que apenas descreve a presença de um cadáver na arena de um circo, expõe as reações da plateia e dos demais envolvidos na cena quando defrontados com esse fato inusitado, fazendo referência ao jogo que se desenvolve entre o real e o ilusório, entre o verossímil e o absurdo.

Nos contos "As marcas do real" e "O assassino ameaçado", o primeiro do livro homônimo e o segundo de Dias melhores, o narrador, ainda segundo Cássio Tavares, não poderia estar em primeira pessoa em nenhum dos dois casos exatamente pela essência do assunto de que eles tratam, ou seja, essas narrativas tematizam objetos concretos e inanimados que não teriam como assumir a voz narrativa sem que o conto se aproximasse das características da fábula. Assim, nesses contos, o narrador estaria

condenado à condição de instância externa abstrata pela natureza do assunto, já que o que tomam como objeto é coisa concreta: no primeiro caso, trata-se de poesia do poeta austríaco Georg Trackl, e no segundo, de um quadro de Magritte. ${ }^{3}$

Em outros três contos, "Passagem de ano", "Rito sumário" e "Fim de caso", todos do livro Dias melhores, a personagem-tema morreu, e o que o relato propõe é a decifração de como essas personagens chegaram às circunstâncias de suas mortes. Nesses contos, seguindo ainda o pensamento de Cássio Tavares, o narrador assemelha-se mais a uma personagem marginal do que a uma instância externa

${ }^{1}$ Modesto Carone, As marcas do real, Rio de Janeiro, Paz e Terra, 1979; Idem, Aos pés de Matilda, São Paulo, Summus, 1980; Idem, Dias melhores, São Paulo, Brasiliense, 1984; Idem, Por trás dos vidros, São Paulo, Companhia das Letras, 2007.

${ }^{2}$ Cássio Tavares, O conto e o conto contemporâneo, São Paulo, 2003, Tese (Doutorado em Teoria literária e Literatura Comparada) - Faculdade de Filosofia, Letras e Ciências Humanas, Universidade de São Paulo.

${ }^{3}$ O levantamento das características do narrador nos três primeiros livros de Modesto Carone foi feito por Cássio Tavares e é nesse estudo que nos baseamos para esse pequeno painel do foco narrativo do autor. As contribuições referentes ao livro Por trás dos vidros são nossas.

${ }^{4}$ No livro lançado em 2007, Por trás dos vidros, esse conto aparece com o título de "Virada de ano". 
abstrata como nos outros contos, uma vez que especula a respeito do percurso que conduz o morto a seu destino, parecendo ser uma figura próxima ou interessada nos eventos narrados, embora em nenhum momento possa ser identificado de quem se trata pelo leitor.

Dos contos inéditos do livro Por trás dos vidros, três podem ser incluídos entre os narrados em terceira pessoa: "Dueto para corda e saxofone", "O retorno do reprimido" e "O natal do viúvo", pois trazem aproximações com esse narrador que, temos a impressão, precisa estar em terceira pessoa, uma vez que a personagem não tem condições de assumir a palavra, como vimos nos contos anteriormente comentados. Em "Dueto para corda e saxofone", uma personagem está prestes a cometer suicídio, procurando e testando os meios mais apropriados e seguros para ter sucesso em seu intento. Primeiro analisa a resistência de um cinto, depois a de uma corda e do nó que deve correr livre; também analisa a eficácia do banco de plástico que servirá de apoio. Em determinado momento, a personagem é interrompida pelo som de um saxofone que, por algum tempo, a desvia de sua empreitada e a faz perceber uma nova postura dos objetos da sala e do prédio em que se encontra, mas essa interrupção, ao final, não é suficiente para demovê-la de seu intento. Um dado interessante, ainda carente de estudo mais apurado, é que, no último parágrafo dessa narrativa, quando a personagem já deu fim à sua vida, um "eu" assume a palavra: "Creio que só bem mais tarde o vento vindo do pátio escancarou as janelas e espalhou os papéis da mesa sobre a trama brilhante do tapete de sisal". ${ }^{5}$

Já o conto "O retorno do reprimido" nos apresenta uma personagem que não está em condições de assumir a palavra por assemelhar-se a um animal ou, pelo menos, por aparentemente lhe faltar a capacidade racional. A narrativa apresenta uma pessoa confinada em uma sala acolchoada, com a porta travada por fora, que morde o tapete, urra, baba, tem acessos de raiva, o que a impede de desenvolver um pensamento claro e objetivo e, talvez por esse motivo, haja a necessidade da utilização de uma voz exterior capaz de descrever sua situação. A técnica da descrição talvez seja o procedimento mais presente nessas narrativas de Carone, principalmente para tentar embasar a atividade racional, quer por meio de um narrador-personagem em primeira pessoa que procura organizar e explicar para si mesmo a situação vivenciada, quer por meio de um narrador em terceira pessoa que busca compor um quadro da situação por ele observada.

Em "O natal do viúvo", a voz narrativa, em terceira pessoa, esforça-se em se aproximar do outro, no caso o viúvo que, como dissemos, permanece sentado na poltrona em um canto da sala escura. As várias investidas dessa voz são percebidas pelo processo de aproximação e recuo executado diversas vezes durante a narrativa. O narrador descreve primeiramente o tempo, a chuva e o viúvo: "É tarde, a chuva bate nos vidros, ele está sentado num canto da sala", O narrador, ao que parece, não percebe nenhuma reação da personagem, então se afasta e descreve a sala: a obscuridade em razão das cortinas descidas, as poucas frestas por onde a luz

${ }^{5}$ Modesto Carone, "Dueto para corda e saxofone", in Por trás dos vidros, São Paulo, Companhia das Letras, 2007, p. 27. 
passa. Novamente, volta-se para o viúvo, mas apenas para confirmar a primeira impressão: "ele está parado ou permanece parado", confirmação que estará sempre modulada pela imprecisão, pois "não é possível registrar nada com nitidez". ${ }^{6}$

A narração se afasta um pouco mais para descrever, agora, os carros que passam chiando pela rua; volta-se para o quintal - "um ruído de folhas" - e novamente para o interior da casa descrevendo objetos que poderiam ser usados na noite natalina: copos, toalha, pratos, talheres, guardanapos, velas. A voz aproxima-se outra vez do viúvo que não esboça movimento seguro: "Ele não fixa o olhar na mesa pois conserva a cabeça baixa ou apoiada na mão direita, talvez na esquerda". Ao insistir, a voz narrativa parece perceber certa atividade interior da personagem, embora tudo continue opaco para o narrador:

Mas ele não é cego, olha para dentro e remexe, apalpa o que vê, as imagens vão de um lado para outro, rodopiam, escondem-se atrás da coluna de gesso e desaparecem sem deixar vestígio. ${ }^{\top}$

O narrador, diante da impossibilidade de captar algo com maior precisão, afasta-se novamente se atendo à descrição do ar espesso e da criada que varre a sujeira deixada pela coluna de gesso que acaba de desabar. Nessa passagem, que inaugura o segundo terço da narrativa, deparamos com essa imagem da coluna atrás da qual as imagens interiores do viúvo rodopiam e se escondem. Coluna que pode ser associada a algo que sustém, um apoio, um alicerce, mas frágil em demasia devido ao material de que é composta: o gesso. Acentua-se, assim, a indefinição, a impossibilidade de distinguir temporalidades, uma mistura entre o presente e o passado, pois o que se segue é a lembrança de uma cena remota: a campainha toca, a esposa abre a porta para a filha, a sala se ilumina, o filho chega e abraça "as duas mulheres de perfil idêntico". A mesa está posta, as velas acesas, a criada entra sorrindo com uma travessa nos braços. Eles comemoram, brindam, sorriem. Mas emerge um clarão e "a cera começa a derreter". A cena começa a derreter, não se refazendo. A esposa volta-se para a poltrona "faz um gesto com as mãos, insiste, insiste". Novamente a voz narrativa se afasta, contempla a paralisia e a mudez desse viúvo mortificado pela dor. Afasta-se ainda mais, fixa-se nas cortinas fechadas, na noite que avança; volta para a personagem que continua imóvel, que talvez apoie o rosto nas mãos ou cruze as pernas. E mais uma vez se afasta: o sino que não soa, a sombra que desliza, as nuvens que se afastam, a porta lateral trancada, a campainha muda, o portão de ferro coberto pela hera, as vidraças vazias. O viúvo continua sentado na sala.

A pungência da dor da perda é latente no conto. Como em um processo de "mineração", ${ }^{8}$ a voz narrativa - essa voz sem nome e sem indicação - tenta escavar

${ }^{6}$ Carone, "O natal do viúvo", op. cit., p. 11.

${ }^{7}$ Idem, ibidem, p. 12.

${ }^{8}$ Lembramos aqui um belíssimo poema de Carlos Drummond de Andrade, "Mineração do outro", no qual, apesar de referir-se ao relacionamento amoroso, lembra-nos o movimento do narrador desse conto de Carone, em sua tentativa de aproximar-se da personagem: "Os cabelos ocultam a 
o outro, investe diversas vezes, aproximando-se e afastando-se numa insistência que avança um pouco mais a cada tentativa, mas que não é violenta. É, antes, uma discreta aproximação que respeita o sofrimento alheio, mesmo quando o sentido escapa - e ele sempre escapa, pois não há mais nenhuma possibilidade de domínio, nenhuma possibilidade de plenitude de saberes -, percebemos, apenas, o vaivém dessa voz na tentativa de contato com o ser que sofre.

Por outro lado, o narrador consegue descrever, por um instante, o interior da personagem no momento em que a cena de um natal passado invade a narrativa, momento no qual a família estava reunida e feliz. Há, aqui, um movimento que pode nos sugerir a onisciência de um narrador tradicional, porém, não existe mais a possibilidade de um narrador como esse. É bem provável que qualquer aproximação, como o da empregada que varre o chão, e para quem ele faz um gesto de impaciência ou de dor, passe a ser algo incômodo para o viúvo, pois o processo de trabalho do luto gasta todas as suas energias e consome, igualmente, seu corpo físico.

\footnotetext{
Mas ele não é cego, olha para dentro e remexe, apalpa o que vê, as imagens vão de um lado para outro, rodopiam, escondem-se atrás da coluna de gesso e desaparecem sem deixar vestígio. $\mathrm{O}$ ar que ele respira é espesso, a neblina sobe do chão, a coluna vacila, de repente desaba, os pedaços se espalham pelo chão sem barulho. A criada de avental está varrendo o assoalho, a vassoura de pêlo trabalha como um autômato, a moça vira as costas para a sala, some pela porta da copa. ${ }^{9}$
}

O luto, como se sabe pelos estudos psicanalíticos de Freud, é o sentimento de dor ou pesar originado pela consciência da perda de uma pessoa amada ou alguma abstração que se coloque em seu lugar: pátria, liberdade, ideal. A reação a essa consciência da perda é um estado de ânimo doloroso, um desinteresse pelo mundo externo; esse se torna pobre e vazio na medida em que não se relaciona com a memória do morto. Há, no trabalho do luto, uma tendência ao isolamento e ao silêncio para que, com o passar do tempo necessário, o ego liberte sua libido do objeto perdido. Mas enquanto dura, o trabalho do luto absorve todas as energias do ego e pode provocar a paralisia do sujeito, inclusive a corporal, como presenciamos no conto de Modesto Carone.

Cabe registrar, ainda, que o luto difere da melancolia por esta apresentar, além das características descritas para aquele, um rebaixamento do sentimento de autoestima, pois introjeta o objeto perdido, ou seja, é uma perda inconsciente e não se refere a algo que realmente morreu, mas faz que o ego se sinta morto, na medida em que existe uma impossibilidade de reconquista e uma identificação narcísica entre o ego e o objeto perdido. No melancólico há uma tendência para a comunicação, para o autodesnudamento, geralmente atribuindo a si mesmo características

verdade./Como saber, como gerir um corpo/Alheio?/Os dias consumidos em sua lavra/Significam o mesmo que estar morto./ [...] /O corpo em si, mistério: o nu, cortina/De outro corpo, jamais apreendido,/Assim como a palavra esconde outra/Voz, prima e vera, ausente de sentido" (Carlos Drummond de Andrade, "Lição de coisas", in Nova reunião, Rio de Janeiro, José Olympio, 1983, v. 2, p. 379-80).

${ }^{9}$ Carone, "O natal do viúvo", op. cit., p. 12. 
desmerecedoras ou indignas, atitude que, ao fim, revela o desejo de queixar-se de outra pessoa que amou, ama ou deveria amar. Na melancolia, não tendo sido aceita a perda do objeto, ele se internaliza e, assim, a queixa contra si mesmo é na verdade a queixa contra o objeto perdido. As causas do estado melancólico ultrapassam a morte simplesmente e podem abranger todas as situações de ofensa, desprezo e decepção.

Entre essas duas condições - luto e melancolia -, Freud afirma que o luto é considerado normal; sua elaboração demanda tempo e energia, mas, embora acarrete graves desvios da conduta normal da vida, não deve ser perturbado, pois não é uma condição patológica como, algumas vezes, a situação melancólica o é. No trabalho do luto, ainda que haja uma resistência à constatação da perda e, assim, à aniquilação do objeto, o sujeito não escapa a essa perda e, mesmo em meio à dor, ainda consegue percebê-la e constatar que a vida não é dominada em nada por suas forças. ${ }^{10}$

Ao fim do processo de luto, o ego intui, dolorosamente, não poder controlar o rumo de sua existência. Nesse momento, o sujeito depara com a tarefa de se defrontar com o objeto perdido e analisar suas relações com esse - é o tempo mais difícil e complexo da reelaboração, pois deixa o campo estritamente narcísico e entra no terreno da ética, de modo que é a responsabilidade do sujeito diante do objeto perdido que está agora em causa. ${ }^{11}$

No conto de Carone, o viúvo parece estar em um momento anterior a esse: ele está no momento da dor mais profunda em que o trabalho do luto ainda não chegou à sua etapa final. A voz narrativa, pelas várias aproximações que faz, parece tentar compreender a situação do viúvo, mas pelo modo como essa voz se configura, essa compreensão não é possível, visto estar atrelada apenas à pessoa que sofre. A dor é compreendida apenas pelo sujeito do trabalho do luto, já que a realidade psíquica que ele vive não se deixa apreender para fora de sua intimidade psíquica e de sua fantasmagoria. Durante todo o conto, o narrador se afasta e se aproxima, em um movimento que apenas consegue flagrar a suspensão solitária do ritmo dos dias, aparentemente porque sabe ou pelo menos pressente nada poder fazer para alterar ou minimizar essa situação.

À maneira das narrativas de Beckett, como aparece na epígrafe do conto, ${ }^{12}$ o viúvo é um homem sozinho, confinado a um espaço de recolhimento e cuja

\footnotetext{
10 "O sofrimento nos ameaça a partir de três direções: nosso próprio corpo, condenado à decadência e à dissolução, e que nem mesmo pode dispensar o sofrimento e a ansiedade como sinais de advertência; do mundo externo, que pode voltar-se contra nós com forças de destruição esmagadoras e impiedosas; e, finalmente, de nossos relacionamentos com os outros homens. O sofrimento que provém dessa última fonte talvez nos seja mais penoso do que qualquer outro" (Sigmund Freud, "O mal-estar da civilização", in Obras psicológicas completas de Sigmund Freud, Rio de Janeiro, Imago, 1974 , v. XXI, p. 95).

${ }^{11}$ Sigmund Freud, "Luto e melancolia", trad. Marilene Carone, Novos Estudos Cebrap, n. 32, p. 128-42, mar. 1992.

12 A epígrafe é: "à maneira de Molloy de Beckett". Comentando a respeito desse conto, Modesto Carone afirma: "Escrevi um conto que me foi inspirado por Beckett. [...] Chama-se 'O Natal do viúvo'. Há duas frases de Beckett que realmente me deram o conto: 'Era noite. Estava chovendo.'
} 
devastação interior o impede de agir, paralisando-o, sem que vise a uma transformação do presente, permanecendo fixo ao passado. Não há rememoração, no que essa se aproxima de uma memória ativa que gere modificações, mas, ao contrário, percebemos a ruminação do passado ao qual ele imovelmente se ata.

Na narrativa de Samuel Beckett, Molloy (1947-1948), há um trajeto que é percorrido pela personagem em busca de sua história e que leva à sua crescente degradação física - no início a perna problemática da personagem incomoda, mas não a impede de andar de bicicleta, indo sempre de um espaço aberto para um fechado e vice-versa; no decorrer da narrativa, porém, ela passa a usar muletas e depois a rastejar, terminando na imobilidade, dentro de um quarto que acha ser o de sua falecida mãe, com a qual não possuiu nenhum laço afetivo. $O$ trajeto percorrido, portanto, é o da busca da mãe, do passado e da difícil recuperação da memória e das experiências que constituem o próprio eu, que, ao fim, acabam na incapacidade do narrador - em primeira pessoa - de construir uma narrativa capaz de dar conta da realidade precariamente recuperada, da sua própria história e do próprio processo de lembrar.

A linguagem que o livro de Samuel Beckett nos apresenta é toda pautada pelas incertezas e dificuldades. Mesmo a impossibilidade de construção da própria linguagem está presente na narrativa, uma vez que mesmo a memória do protagonista pode enganar. Logo no início de Molloy podemos encontrar uma atmosfera bastante parecida com a do conto de Modesto Carone:

Tudo se esfuma. Mais um pouco e você fica cego. Está na cabeça. Ela não funciona mais, ela diz, Eu não funciono mais. Você fica mudo também e os ruídos enfraquecem. Mal se atravessa o limiar é assim. É a cabeça que deve estar cheia. De modo que você diz a si mesmo, Chegarei bem desta vez, depois mais uma, depois será tudo. É difícil formular este pensamento, pois é um pensamento, num certo sentido. ${ }^{13}$

Percebemos a tentativa de atravessar o limiar, depois do qual tudo se esfuma, uma fronteira mental, para aproximar-se da vida que deseja narrar, no caso de Molloy, ou da vida que é narrada, no caso do viúvo de Carone. No conto do autor brasileiro, o narrador em terceira pessoa tenta a aproximação, sempre frustrada, como acompanhamos anteriormente. O recurso linguístico da imprecisão está, nas duas narrativas, presente principalmente no grande número de advérbios de dúvida que caracterizam a linguagem e na oscilação do foco narrativo, no caso do texto caroniano.

No conto de Carone há uma insistência do narrador em descrever a posição imóvel da personagem. Por toda a extensão do conto são inúmeras as referências à imobilidade física do viúvo, que não deixa a sua posição inerte em nenhum momento. Como vimos, em muitas situações, o trabalho do luto gera uma tendência

E depois, no final: 'Não era noite. Não estava chovendo'”. (Ana Paula Pacheco; Priscilla Figueiredo, "Mimese e contradição. Entrevista com Modesto Carone", Rodapé. Crítica de literatura brasileira contemporânea, São Paulo, n. 1, p. 206, nov. 2001.

${ }^{13}$ Samuel Beckett, Molloy, São Paulo, Globo, 2007, p. 24. 
ao isolamento e ao silêncio provocando, pelo consumo de suas energias, uma paralisia do sujeito. O viúvo do conto caroniano permanece ao longo de toda a narrativa imóvel em sua poltrona, seus gestos são mínimos e muitas vezes eles são apenas uma sugestão do narrador, a descrição se prende somente a uma intenção da personagem ou, mais remotamente, a uma suposição de movimento somada às possíveis consequências, caso tal movimento ocorresse.

Talvez apóie o rosto numa das mãos ou cruze as pernas mas não se percebe nenhum movimento. A obscuridade é maior porque as cortinas estão descidas e a luz só filtra por algumas frestas. ${ }^{14}$

[...] ele está parado ou parece parado na poltrona do canto da sala. Provavelmente os olhos permanecem fechados e se as pálpebras se abrem a vista acusa tonalidades de cor na quina de um móvel. ${ }^{15}$

Ele não fixa o olhar na mesa pois conserva a cabeça baixa ou apoiada na mão direita, talvez na esquerda. Se olhasse não veria nada porque lá também não há luz. ${ }^{16}$

[...] agora é possível que ele se mova no assento da poltrona, faça menção de ir até a janela para abrir as cortinas. ${ }^{17}$

[...] ele quer dizer alguma coisa e emudece, talvez ele chore. ${ }^{18}$

Talvez apóie o rosto nas mãos ou cruze as pernas mas não se nota nenhum movimento. ${ }^{19}$

Ele está sentado num canto da sala, quem sabe estique a cabeça e os braços no escuro. ${ }^{20}$

Essa conjuntura física de paralisação pode aproximar a personagem, metaforicamente, da situação da própria esposa, em sua imobilidade de morte. Nesse caso, o viúvo está psiquicamente desvitalizado também, pois não esboça nenhum movimento que possa trazê-lo mais próximo da vida que do depauperamento físico e mental em que se encontra um cadáver. A dor da perda é tamanha que o viúvo contamina-se com a morte e deixa-se ficar inerte e abúlico em sua poltrona no canto da sala, em um ambiente escuro e sem ligação direta com o presente. Seu corpo, contaminado e vencido pela perda, permanece paralisado como se estivesse não só destroçado pela dor, como falecido, uma falência psíquica que exaure todas as suas forças vitais.

Nessa condição, existe uma contraposição entre a imobilidade da personagem e o movimento do narrador que percorre um tempo e um espaço diferentes. Para a personagem existe uma presentificação fantasmagórica de um tempo anterior e já morto em razão da impossibilidade de retorno. Esse tempo, entretanto, contrapõe-se ao momento da narrativa, pois o narrador busca o tempo presente, descrevendo o aqui e o agora, mas fica sempre sem poder ir muito além ou se aprofundar na narrativa (ou escavar o outro, para lembrar Drummond), já que as temporali-

\footnotetext{
${ }^{14}$ Carone, "O natal do viúvo", op. cit., p. 11.

${ }^{15} \mathrm{Idem}$, ibidem.

${ }^{16}$ Idem, ibidem, p. 11-12.

${ }^{17}$ Idem, ibidem, p. 12.

${ }^{18}$ Idem, ibidem, p. 13.

${ }^{19} \mathrm{Idem}$, ibidem.

${ }^{20} \mathrm{Idem}$, ibidem.
} 
dades são extremamente diversas. Há o presente do narrador e o passado da personagem, temporalidades que se opõem por todo o conto.

Essa dificuldade do narrador na apreensão de sentido do conto ou da própria personagem fica evidente para o leitor, pois esse percebe a limitação da voz narrativa em alcançar o que se passa com esse viúvo. Mesmo no momento em que o tempo passado assume o primeiro plano do conto, com a presentificação de outro natal, a voz narrativa parece apenas acompanhar ou permitir a entrevisão do impalpável, daquilo que se passa no interior dessa personagem.

A campainha toca, toca, o chiado das rodas no asfalto abafa o toque remoto, ela toca outra vez, sobrevém o silêncio. Os passos se aproximam, o salto dos sapatos bate nos tacos, a esposa abre a porta, introduz a filha na casa com um beijo, as duas passam pela poltrona falando em surdina, agora é possível que ele se mova no assento da poltrona, faça menção de ir até a janela para abrir as cortinas. No centro da sala iluminada a filha está conversando com a mãe, elas mantêm os dedos enlaçados, o filho desce a escada em caracol e abraça as duas mulheres de perfil idêntico. A mesa foi posta, as velas vermelhas ardem nos castiçais, a moça de avental entra sorrindo com uma travessa nos braços. Os filhos chegam à poltrona do canto da sala, erguem as taças, pelo meio dos dois a mulher espia para ele, sorri, os dentes são brancos, as maças do rosto coradas e da linha alva do pescoço emerge um clarão. A cera começa a derreter, não se refaz, as figuras balançam como recortes de papelão no vento, o sino da igreja está batendo alto e uma rajada abre as vidraças sobre a praça. As árvores decoradas estão molhadas de chuva, os canteiros floridos, ele vê a família abraçada junto à janela, a mulher ainda se volta para a poltrona, faz um gesto com as mãos, insiste, insiste, ele quer dizer alguma coisa e emudece, talvez ele chore. ${ }^{21}$

Nesse trecho do conto e em outros, ${ }^{22}$ podemos perceber, aliada às temporalidades distintas, dois espaços que igualmente se contrapõem - o espaço do viúvo, preso em seus pensamentos e na sua interioridade, e o espaço percorrido pelo narrador que vaga pela sala e pelos arredores da casa, mas sempre se movimentando por recintos abertos se comparados ao quase encarceramento da personagem em sua sala, em sua poltrona e em si mesmo devido à angústia e à dor. Tanto o espaço habitado pela personagem ao recordar o passado quanto o espaço percorrido pelo narrador são descritos com riqueza de detalhes e mostram que há, nessa narrativa, dois mundos incomunicáveis e igualmente precisos, embora a personagem e tudo o que gira em torno dela não se deixem apreender pelo narrador ou por ninguém, inclusive pelo leitor.

${ }^{21}$ Carone, "O natal do viúvo", op. cit., p. 12-13.

${ }^{22}$ Podemos ainda apresentar as seguintes passagens do conto como exemplos do espaço percorrido pelo narrador, todos evidenciando grande detalhamento: "Os carros passam pela rua da frente chiando os pneus no asfalto e alguma coisa estremece na casa, um ruído de folhas, o tinido de um cristal" (Carone, "O natal do viúvo", op. cit., p. 11); "o sino da igreja está batendo alto e uma rajada abre as vidraças sobre a praça. As árvores decoradas estão molhadas de chuva, os canteiros floridos..." (idem, ibidem, p. 13); "Pelas cortinas fechadas percebe-se que a noite avança..." (idem, ibidem); "O sobrado se destaca num halo de luz que vem de cima e tinge as nuvens de rosa, talvez um sopro as leve logo para longe. A porta lateral da casa está trancada, a campainha muda, o portão de ferro coberto pela hera, as vidraças vazias" (idem, ibidem). 
A descrição de um natal passado poderia atestar a presença de um narrador onisciente, mas essa possibilidade é negada por todo o restante do conto em que as descrições temporais e espaciais, pelo menos em tese mais fáceis de serem confirmadas, são uma a uma desmentidas. Assim, no início do conto as afirmações "É tarde, a chuva bate nos vidros, ele está sentado num canto da sala" são repetidas e negadas no fim do conto: "É tarde e a chuva bate nos vidros. Não era tarde. Não estava chovendo".

Como essas, outras afirmações do conto são negadas durante a progressão da narrativa. A afirmação

Os copos estão enfileirados sobre a toalha ao lado dos pratos e talheres e dos guardanapos dobrados como um par de asas na penumbra. ${ }^{23}$

é desmentida pelo período seguinte

Os vidros e os metais não cintilam, as velas vermelhas dormem nos castiçais, o mais provável é que não tenham saído dos armários e da cristaleira. ${ }^{24}$

O sino da igreja e a campainha que antes tocavam, estão agora mudos; as janelas antes cobertas pelas cortinas e abertas pelo vento estão agora vazias:

O sino não soa, não há sinos por perto, a sombra desliza sobre as mesas e os armários. [...] A porta lateral da casa está trancada, a campainha muda, o portão de ferro coberto pela hera, as vidraças vazias. ${ }^{25}$

Verifica-se, assim, a dificuldade, ou mesmo a impossibilidade de distinguir temporalidades que sejam plenamente identificáveis tanto para a personagem quanto para o próprio narrador. Para a primeira, possivelmente pelo próprio processo de trabalho de luto, os tempos do passado e do presente estão embaralhados em sua consciência, na medida em que o mundo como ele se apresenta não possui nenhum atrativo, visto não ter mais a esposa ao seu lado. Para o narrador, as temporalidades estão também pouco definidas, ele não possui segurança em seu trabalho, como ele mesmo afirma em alguns momentos do conto:

Não é possível registrar nada com nitidez, ele está parado ou permanece parado no canto da sala. ${ }^{26}$

As lágrimas devem rolar no escuro, escorrer pelo peito, pingar no tapete; não é exato descrever o que acontece. ${ }^{27}$

Há um respeito pela dor por parte desse narrador que não se impõe como onisciente, uma vez que ele não conhece nem sabe nada, como dissemos. O que

\footnotetext{
${ }^{23}$ Carone, "O natal do viúvo", op. cit., p. 11.

${ }^{24}$ Idem, ibidem.

${ }^{25}$ Idem, ibidem, p. 13.

${ }^{26}$ Idem, ibidem, p. 11.

${ }^{27}$ Idem, ibidem, p. 13.
} 
está sendo problematizado no conto, portanto, é o fato de não apenas a interioridade, mesmo se apresentando em circunstâncias detalhadas, ser indevassável, como aquilo em que o narrador depositava sua confiança - isto é, o detalhamento da cena, em seus elementos espaciais, também não poder servir de base para seu trabalho, já que a precisão lhe escapa e a temporalidade e a espacialidade, bem como as circunstâncias, deixam de ser algo definitivo e certo. A narrativa assume um aspecto de circularidade em que nada pode ser objetivamente confirmado ou sancionado como verdadeiro.

A preferência pelo tempo verbal do presente do indicativo, nessa e em muitas outras narrativas do autor, pode apontar para a continuidade de um estado de coisas que avança sem nenhuma possibilidade de mudança, configurando-se em uma presença durativa da alienação, da violência e da morte. Temas esses que permeiam a obra de Modesto Carone como um todo. Segundo o próprio autor,

a presença da morte em Por trás dos vidros talvez tenha uma explicação. Em primeiro lugar, ela é o estágio terminal da violência urbana, em segundo porque de acordo com a psicanálise, que entende do assunto, o homem tem três noivas: a mãe, a esposa e a morte. É possível que eu esteja noivando pela última vez, mas isso não significa que esse noivado seja breve. Montaigne dizia que filosofar é aprender a morrer. ${ }^{28}$

As diversas nuanças da alienação, com que deparam ou em que se encontram as personagens de Carone, mostram a falta de consciência e a reificação a que todos os homens estão sujeitos. Os restos da subjetividade, tão celebrada em séculos anteriores, são o foco desses textos em que a vida se encontra cercada e fragmentada, em que nada é seguro, senão o incerto. A realidade deste mundo torna-se, por extensão, um processo de aderir, de colar-se ao que já não existe mais na sociedade, ou seja, algo que possa transmitir alguma segurança. Nesse sentido, tudo se torna trabalho de luto, ou, ao menos, objeto de suspeita desse narrador, de que o próprio tempo é a marca da morte permanente.

A obra de arte, ao formalizar aspectos sociais, salienta para o leitor a complexidade das relações sociais, em que o mundo, administrado e regulamentado por instâncias desconhecidas, faz de cada um nós um títere e uma engrenagem que pode ser facilmente substituída. A obra literária de Modesto Carone não facilita ou edulcora a leitura, mas aponta um caminho que pode ser o da percepção, mesmo que mínima, de nossa realidade. Ao utilizar-se da linguagem como instrumento, trabalhando-a com mestria, traz em seu cerne a marca das obras de arte que permanecem e apresenta o selo daquelas que podem ajudar a quebrar o gelo que há dentro de nós, como disse Kafka, e nos mostrar, por meio da forma conciliada da obra literária, o seu duplo dialético: que a sociedade é fragmentada, dividida, violenta e sem sentido.

\footnotetext{
${ }^{28}$ Modesto Carone, "Diante do vazio, a fabulação". Entrevista cedida por e-mail a Rogério Pereira para o jornal literário Rascunho [online] Disponível em: <http://rascunho.rpc.com.br/index.php?ras $=$ secao.php\&modelo $=2 \&$ secao $=5 \&$ lista $=0 \&$ subsecao $=0$ \&ordem $=1801>$ Acessado em: 8 nov. 2009 .
} 